\title{
RESEARCH REPORT \\ EFFECTIVENESS OF NEURAL MOBILIZATION AND STRETCHING EXERCISE FOR THE MANAGEMENT OF SCIATICA
}

\begin{abstract}
\section{OBJECTIVE}

To find out the effectiveness of neural mobilization and stretching exercise for the management of sciatica
\end{abstract}

\section{BACKGROUND}

Sciatica is described as pain, radiating to the leg below the knee joint and caused by irritation of the sciatic nerve or nerve trunk. There are many treatment options for the management of sciatica, including stretching exercise and neural mobilization.

\section{MATERIAL AND METHODS}

This study was a Randomized Controlled Trial. 94 patients from physical therapy OPD of tertiary care hospitals, were participated in this study. Hence, 47 patients were randomly allocated into each group A and B. Before and after the nine treatment sessions, both groups were assessed with VAS, SLR ROM and Quebec back pain disability scale. In group A, neural mobilization with conventional therapy (heat and TENS) was applied, while stretching exercise with same conventional therapy was applied to group B.

\section{RESULTS}

It was observed that both treatments were helpful in reducing the symptoms. The analysis showed significant improvement ( $p$-value $<0.05$ ) in the SLR to $60.851^{\circ} \pm 6.86^{\circ}$ and $Q u e b e c$ score to $23.617 \pm 3.125$, after the stretching exercise. Hence, both treatments were equally effective in reducing pain ( $\mathrm{p}$-value $>0.05$ ).

\section{CONCLUSION}

Stretching exercise is more effective in the improvement of SLR and disability. Furthermore, both techniques are helpful in the management of pain.

\section{KEY WORDS}

Sciatica, Stretching, Neural Mobilization, Straight Leg Raising, Visual Analogue Scale, TENS.

\author{
Sidra Zahid \\ Student PPDPT \\ Ziauddin College of Physical Therapy \\ Ziauddin University \\ sidra.zahid05@gmail.com

\section{Ghazala Noor Nizami} \\ Assistant Professor \\ Ziauddin College of Physical Therapy \\ Ziauddin University \\ ghazi_17@hotmail.com
}

[Zahid S, Nizami GN. Effectiveness of Neural Mobilization and Stretching Exercise for the Management of Sciatica. Pak. j. rehabil. 2014;3(2):11-15] 


\section{INTRODUCTION}

The lumbosacral radicular syndrome (LRS), which is well renowned as sciatica, is a condition that is pigeonholed by the pain radiating in the leg below the knee joint, covering one or more than one dermatomes. It can be escorted by occurrence of the nerve root tension or nervous deficits ${ }^{1-4}$. Disorders related to the lumbar spine are the fifth most mutual disorder in the classification of diseases and in the cost of hospital care. In Netherlands, occurrence of the sciatic pain is estimated about five out of thousand persons in a year ${ }^{5}$. Sciatica accounts for larger expenses, ensuing in the inattentive from job and disability, than any other nature of disease. Disability interlocked to the LRS, subsidizing to a substantial economic problem, so that every year only in U.S. it goes directly above just about fifty billion. Health associated disbursement in people with LRS is also sixty present bigger as compare to those people who are not affected with LRS 6 . In many studies, it has been revealed commonly that general practitioners did not follow the approaches related to the recommendation to Physical therapy (PT). Usually lesser amount of the clients with LRS was referred for physical therapy ${ }^{7}$. Furthermore, knowledge about the effectiveness of physical therapy treatment in LRS is not known commonly ${ }^{8}$. Radiculopathy is pronounced as a pain initiating in the nerve or nerve trunk and triggered due to the unknown provocation of nociceptive afferent filaments in the spinal nerve or in the roots or by further neural related contrivance. Rendering to the above explanations of sciatica, this situation is undoubtedly define as the method of radiating pain and that one designated as a peripheral nervous system ${ }^{9-11}$ related condition. Overall Sciatica is a mutual situation and through the life time prevalence of sciatica in whole life of a human fluctuating from thirteen percent to forty percent ${ }^{12}$ and the universal annual frequency of the sciatica is from 9.3 to 25 percent ${ }^{13}$.

The Domenico Cotuga, an Italian anatomist (1736-1822), composed the 1stbookon sciatica in 1764 and for a long time sciatica was written as Cotugno'sillness ${ }^{14}$. Cotuga was the main person who explained the amendment between the sciatic pain and throbbing pain linked to the LBP. In nineteenth century, it was alleged that sciatica is instigated by rheumatism disorders and lead to the swelling of the sciatic nerve ${ }^{14}$. The disc located between the vertebrae, was first determined the rooting cause of sciatica in the 20th century by Schmorl and Andrae ${ }^{15}$. Many studies publicized that many environmental and inherent characteristics presumed to be the basis of sciatica, such as age, genetic factors, and occupation $^{16-19}$. A Cross-sectional research was done on two thousand nine hundred forty six women and two thousand seven hundred twenty seven men. It disclosed that male or female, not mass of the body partaken any impression over the development of the sciatica but over body mass has been interrelated to the low back pain ${ }^{16}$. There are many components related to the treatment of sciatica, comprising analgesic medication, manipulation, surgical decompression and variation in the treatments delivered by physical therapy, including specific condition related exercises, functional rehabilitation, manual mobilization techniques and manipulation, electrotherapy, mechanical machines and other physical components ${ }^{20}$.

Neurodynamics is a more predictable word, indicates to integrate biomechanics of the tissue, physiological and morphological functions related to nervous system.
Regardless in the fundamental theory, established that nervous system is proficient to become accustomed to the mechanical loads and its must go through contradictory mechanical actions including lengthening, sliding, cross-sectional alteration, angulation and compression. These self-defending systems become unproductive. The nervous system predisposed to inflammation, decreased blood supply, fibrosis and that leads to the decreased oxygen consumption ${ }^{21,22}$. All these factors can transform neurodynamics. When neural mobilization is used for treatment of confrontational neurodynamics, the fundamental goal is to endeavor the refurbish dynamic stability in the comparative motions of nervous tissue and the adjoining mechanical interface ${ }^{23}$. In this manner, it lowers the central burdens on the nervous material and therefore assembles the most adequate physiological effect. The benefits that result from this procedure include acceleration of nerve gliding, decline in the nerve adherence, spreading of pain causing substance, improvement in neural circulation and enhancement of axoplasmic flow. Additionally, Lopes et al established that the Neural Mobilization procedure leads to enriched muscle power of the quadriceps muscle that may be interrelated with increased axoplasmiccirculation ${ }^{24}$. Furthermore, study focused on technique used with rats having neuronal pain that was assessed by the computerized test. It stated that the neural mobilization procedure leads to the refurbishing of sciatic nerve by aggregate the appearance of zero nerve growth factor ${ }^{25}$.

Stretching is the most collective maneuver utilized in many rehabilitation events. Stretching is ordinarily given to increase muscle flexibility, range of motion (ROM) and for the management of pain. Chan and colleagues ${ }^{26}$ categorized that eight weeks of continuous static stretching can increase muscle extensibility, flexibility and range of motion, related with an upsurge in stretch tolerance of the muscle. Stretching is a common program performed by sportsmen, geriatric peoples, any person involved in a health related or rehabilitation programs. Despite the fact, neural mobilization and static stretching exercises are beneficial properties by faltering outcomes obtainable in the literature ${ }^{27}$. A study which was completed by Saher M, in journal of American science 2011, authorizes that straight leg raising (SLR) stretching may be valuable for the treatment of clients with low back dysfunctions ${ }^{28}$.The SLR test is universally done for the evaluation of clients having complaint of lumbar spine dysfunction and included in the limited pointers that have been publicized to discriminate the point of functional disability from low back dysfunctions $^{29}$. Likewise, it has been pointed out that enlightening the range of SLR has boundless end product in persistent normal movement and plummeting the degree of impairment due to low back dysfunction. The focus of this research was to determine the effectiveness of neural mobilization and stretching exercise on patients with sciatica and evaluate the most effective treatment for the sciatica.

\section{MATERIALS AND METHODS}

\section{Study Design}

The design of this study was Randomized Controlled Trial (RCT).

\section{Sample Size}

Sample size was ninety-four patients. 


\section{Study Setting and Participants}

94 patients who met inclusion criteria were selected from outpatient department (OPD) of physical therapy of tertiary care hospitals in Karachi, Pakistan.

\section{Duration of the Study}

Total duration of the study was one year.

\section{Sampling Technique}

The sampling technique which is used to select the patients was simple random sampling technique. The selected clients were in discriminately distributed into two groups (group A and B), 47 patients in each group.

\section{Inclusion Criteria}

Male and female patients with complain of sciatica; aged between 20 to 60 years were included. Patients with low back pain, having symptoms from two weeks to three month and the production of symptoms on nerve tension test, that is, SLR must be 35 degrees or more were included in this study.

\section{Exclusion Criteria}

Patients who planned migration to another city or country within one month or involved in any other physical fitness program were excluded. Patient with RED FLAGS (tumor, osteoporosis, spinal fracture, metastasis), or having history of major systemic and psychological illness (depression, schizophrenic) were also excluded from this study.

\section{Ethical Consideration}

Written consent was taken from the participants. All personal information of the participants was kept confidential. Attention was given on privacy, hygiene and environment of the treatment. Permission was also taken from the management of the tertiary care hospital.

\section{Patient Evaluation Procedure}

Patients were finalized with some self-reported measures, followed with a client medical background and physical assessments accomplished with the help of physical therapist.

\section{Demographic and Subjective Dato}

The history consist of demographic information (such as age, gender and occupation), past medical history, location and nature of symptoms, previous episodes of symptoms, relieving and aggravating activities and leisure activities.

\section{Pain and Other Symptoms}

Patients detailed the area of their symptoms on the body chart to define the extent to which centralization occurred before treatment, which was determined according to the procedures described by Werneke et $\mathrm{al}^{30}$. The visual analogue scale (VAS) consists of ten numerical numbers starts from zero (no pain) to ten (intense pain) and was used to determine the intensity of pain from its lowest to intense degree ${ }^{31}$.

\section{Functional disability}

The activity of daily living of every client was checked by Quebec ${ }^{32}$ Back Pain Disability Scale. This consists of 20 variety of queries related to LBP and disability in daily activities. For every query, the client ticked one choice from the six options that accurately explained his or her disability. If the 1stoption was mentioned, then the score is 0 , if the last option was mentioned then the score is 5. The minimum score is 20 and the maximum score is 100 . Higher scores correlate to greater disability. The score was calculated with the help of following formula:

Percent of maximal disability

$=(($ score $)-20) / 80 * 100 \%$

\section{Range of Motion}

The range of motion of hip joint for sciatica was measured with the help of goniometer by performing SLR.

\section{Re-Evaluation}

At the finishing point of 9 physical therapy sessions, clients of treatment groups (group A and B) were re-examined with the help of VAS, SLR and Quebec back pain disability score.

\section{Interventions}

The clients of group A ( $n=47)$ were treated with neural mobilization along with conventional treatment. Neural mobilization was given for 10 minutes per session, including 30 seconds hold and 1 minute rest. Whereas patients of group $B(n=47)$ were treated with stretching exercise along with conventional treatment. SLR stretching was given for 10 minutes, with 30 second hold and 1 minute rest in each session. In conventional treatment, moist heat was given for 15 minutes and Transcutaneous Electrical Nerve Stimulation (TENS) was given for 20 minute to both groups. Total 9 sessions of treatment were given to both groups.

\section{Data Analysis}

Data was analyzed using the SPSS version 20. Mean \pm Standard Deviation (SD) was calculated. Independent t-test was applied to compare the improvement between group A and group B, through VAS, ROM of SLR and Quebec back pain disability scale, before and after the 9 sessions of treatment.

\section{RESULTS}

94 patients were taken into two groups, 47 in each group A and group B. Group A was treated with the neural mobilization, and Group B was treated with the stretching exercises. At zero session and at the end of the 9 treatment sessions, visual analogue scale, range of motion of SLR, and Quebec back pain disability scale were measured and the data was analyzed by independent t-test.

After nine sessions of treatment, patients of both treatment groups have showed improvement in SLR, VAS and Quebec back pain disability scale, as it is revealed by the Mean \pm SD of the pre and post treatment. Both neural mobilization and stretching exercise were found to be effective in decreasing the pain on VAS to 2 from 7.4 and 7.8 respectively, and showed no significant difference between both treatments, as the p-value is more than 0.05 . The analysis showed significant improvement in the $\operatorname{SLR}\left(60.851^{\circ} \pm 6.86^{\circ}\right)$ and Quebec back pain disability score $(23.617 \pm 3.125)$ in the group $B$, that was treated with stretching exercise, as the p-value is less than 0.05 . 
Table 1: Analysis of Variables for Group A and Group B

\begin{tabular}{|c|c|c|c|c|}
\hline Variable & Grp & $\begin{array}{c}\text { Pre Rx } \\
\text { Mean } \pm \text { SD }\end{array}$ & $\begin{array}{c}\text { Post Rx } \\
\text { Mean } \pm \text { SD }\end{array}$ & $\begin{array}{c}\text { P- } \\
\text { value }\end{array}$ \\
\hline \multirow{2}{*}{ SLR } & A & $\begin{array}{c}35.532^{\circ} \pm \\
5.827^{\circ}\end{array}$ & $\begin{array}{c}56.170^{\circ} \pm \\
7.388^{\circ}\end{array}$ & \multirow{2}{*}{0.00} \\
\hline & B & $\begin{array}{c}35.957^{0} \pm \\
4.961^{\circ}\end{array}$ & $\begin{array}{c}60.851^{0} \pm \\
6.862^{\circ}\end{array}$ & \\
\hline \multirow{2}{*}{ VAS } & A & $\begin{array}{c}7.468^{\circ}+ \\
0.776^{\circ}\end{array}$ & $\begin{array}{c}2.298 \pm \\
1.061 \\
\end{array}$ & \multirow{2}{*}{0.75} \\
\hline & B & $\begin{array}{c}7.851^{0}+ \\
0.780^{\circ}\end{array}$ & $\begin{array}{c}2.234 \pm \\
0.914\end{array}$ & \\
\hline \multirow{2}{*}{ QUBEC } & A & $\begin{array}{c}69.575^{\circ}+ \\
7.453^{\circ}\end{array}$ & $\begin{array}{c}28.234 \pm \\
6.329\end{array}$ & \multirow{2}{*}{0.00} \\
\hline & B & $\begin{array}{c}67.851^{0}+ \\
8.164^{\circ}\end{array}$ & $\begin{array}{c}23.617 \pm \\
3.125\end{array}$ & \\
\hline
\end{tabular}

Group A: Neutral Mobilization; Group B: Streching Exercise the result showed, the neural mobilization was beneficial for the management of pain. The neural mobilization showed great improvement in pain from 7.468 to 2.298 whereas, stretching exercise was also showed the almost same improvement in the pain. Like our study, other studies $^{35-38}$ also studied the effects of neural mobilization techniques on patients with sciatica and lower extremity symptoms. Scrimshaw and Maher ${ }^{37}$ demonstrated in one year follow-up that neural mobilization did not deliver further benefits to traditional postoperative care. Another study which was conducted in Ambala, India, used neural mobilization and conventional heat therapy as a treatment protocols for the patients with neuromuscular disorders. The result of that study showed significant improvement in range of motion of hip and reduction in pain scale ${ }^{38}$. In our study, improvement in the range of SLR was also found with neural mobilization. However, stretching was more effective in improving that ROM. We can affirm that stretching is a crucial part of the treatment. Hence, this study substantiate that stretching exercise creates a better progress in the management of sciatica than neural mobilization.

This study was limited by many factors, such as use of only VAS for assessment of pain, SLR measurement through goniometer. The patients that had symptoms at less than 35 degrees of SLR were excluded from the study. In addition to this, difficult inclusion criteria were used, while if patients did not establish the classic signs and symptoms of sciatica they were excluded from the study. One more limitation that noticed during the study is the ideal position to attain for an effective stretch for the sciatica is not known. Further studies are essential to explore optimal lumbar spine conformation that would further elaborate the SLR stretch. For the treatment of the individuals with sciatica, this study supports the value of the SLR stretching, as we found that the stretching exercise is magnificent than the neural mobilization.

\section{CONCLUSION}

considered by different researchers. George SZ treated the patients with slump stretching and found the decrease in intensity of symptoms ${ }^{33}$. A study which was done by Saher MAdel in 2011, conducted on 60 patients with the complaint of low back dysfunction, and showed that SLR stretching exercises were beneficial for the management of pain, reduction of pain-related disability and promotion of centralization of symptoms ${ }^{28}$. Cleland et a $\left.\right|^{34}$ conducted a study on patients with non-radicular low back pain. They compared two treatment maneuvers; lumbar spine mobilization and exercise with lumbar spine mobilization, exercise and slump stretching. The patients were received 6 sessions. At the end of the last treatment session, the patients treated with stretching exercises along with lumbar mobilization and exercise, had showed significant improvement in pain, disability and centralization of the symptoms. The result of above study was similar to our study in such a way that we also found significant improvement in SLR and disability score after treating the patients with stretching exercise (group B). In our study, we found significant difference between stretching exercises and neural mobilization, whereas, the above study added slump stretching to the lumbar mobilization and exercises. Though, in our study, stretching exercises were found more effective than neural mobilization, in improving the SLR range of motion and disability score.

In our study, neural mobilization along with the conventional treatment of heat and TENS was used in group A. As
It was concluded that stretching exercise is more effective in the improvement of SLR and disability. Furthermore, both stretching exercise and neural mobilization are helpful in the management of pain.

\section{REFERENCES}

[1] North RB, Kidd DH, Zahurak M, Piantadosi S. Specificity of diagnostic nerve blocks: a prospective, randomized study of sciatica due to lumbosacral spine

[2] Stam J. [Consensus in diagnosing and treatment of the lumbosacral radicular syndrome] Consensus over diagnostiek en behandeling van het lumbosacrale radiculaire syndroom. Ned Tijdschr Geneeskd. 1996; 140(52):2621-2627

[3] Weber H, Holme I, Amlie E. The natural course of acute sciatica with nerve root symptoms in a double-blind placebo controlled trial evaluating the effect of piroxicam. Spine(Phila Pa 1976). 1993 Sep;18 (1 1):1433-1438.

[4] Ostelo RW, de Vet HC, Waddell G, Kerckhoffs MR, Leffers $P$, van Tulder $M$. Rehabilitation following first-time lumbar disc surgery: a systemic review within the framework of the Cochrane collaboration. Spine (Phila Pa 1976). 2003 Feb;28(3):209-218 disease. Pain. 1996;65(1):77-85 
[5] Health Council of the Netherlands. Management of the lumbosacral radicular syndrome (sciatica). The Hague: publication no. 1999/1918; 1999.

[6] Luo X, Pietrobon R, Sun SX, Liu GG, Hey L. Estimates and patterns of direct health care expenditures among individuals with back pain in the United States. Spine (Phila Pa 1976). 2004 Jan: 29(1):79-86.

[7] Luijsterburg PAJ, Verhagen AP, Braak S, Oemraw A, Avezaat CJJ, Koes BW. General practitioners' management of LRS compared with a clinical guideline. Eur J Gen Pract 2005; 1 1:1 13-121

[8] Luijsterburg PA, Verhagen AP, Ostelo RW, van Os TA, Peul WC, Koes BW. Effectiveness of conservative treatments for the lumbosacral radicular syndrome: a systematic review. Eur Spine J. 2007;16(7):881-899

[9] Smeelel JM, Van den Hoogen JMM, Mens JMA, Chavannes AW, Faas A, Koes BW et al. [NHG-guideline Lumbosacral Radicular Syndrome] NHG Standaard Lumbosacraal Radiculair Syndroom. Huisarts en Wetenschap 1996;39:78-89

[10] Frymoyer JW. Back pain and sciatica. N Engl J Med 1988;318(11): 291-300

[1 1] Ibe MON. Surgically Treated Symptomatic Prolapsed Lumbar and Sacral Intervertebral Discs in Females: A Comparative Study of Incidence and Causative Factors and Treatment. Niger J Surg. 2012 Jul-Dec;18(2):61-67.

[12] Hoy D, Bain C, Williams G, March L, Brooks P, Blyth F et al. A systematic review of the global prevalence of low back pain. Arthritis Rheum. 2012 Jun:64(6):2028-2037.

[13] Delaney TJ, Rowlingson JC, Carron H, Butler A. Epidural steroid effect in nerves and meninges. Anesth Analg. 1980 Aug; 59(8):610-4

[14] Fuller HW. On Rheumatism, Rheumatic Gout and Sciatica: The Pathology, Symptoms and Treatment. London: John Churchill; 1852

[15] Brunori A, De Caro GM, Giuffrè R. Surgery of lumbar disk hernia: historical perspective. Ann Ital Chir. 1998 May-Jun;69(3):285-93.

[16] Heliovaara $M$, Makela $M$, Knekt $P$, Impivaara $O$, Aromaa A. Determinants of sciatica and low back pain. Spine (Phila Pa 1976) 1991 Jun;16(6):608-14

[17] Heliovaara M. Body height, obesity and risk of herniated lumbar intervertebral disc. Spine (Phila Pa 1976). 1987;12(5):469-472

[18] Heliovaara M. Risk factors for low back pain and sciatica. Ann Med. 1989 Aug; 21 (4):257-64

[19] Frymoyer J. Lumbar disc disease: epidemiology. Instr Course Lect 1992; 41:217-223

[20] Butler Stafford MA, Peng P, Hill DA. Sciatica: a review of history, epidemiology, pathogenesis, and the role of epidural steroid injection in management. $\mathrm{Br} \mathrm{J}$ Anesth 2007:99(4): 461-73.

[21] Butler DS. The Sensitive Nervous System. Adelaide, Australia: Noi-group Publications. 2000.

[22] Shacklock MO. Clinical Neurodynamics: A New System of Neuromusculoskeletal Treatment. Edinberg, UK: Elsevier Health Sciences 2005.
[23] Bramwell JP. Nerve-stretching as a remedy for sciatica. Br Med J. 1980 Jun;1 (1016):920-921.

[24] Lopes RS, Barja PR, MotosLK, Delmonds FD, Lopes FD, Silva KA et al. [Influence of muscle stretching and neural mobilizationon the quadriceps muscle strength]. Influência do alongamento muscular e da mobilização neural sobre a força do músculoquadríceps. Con ScientiaeSaude. 2010:9(4):603-609

[25] Gladson RFB, Taciane SS, Danilo LT, Adriano PC Alberito RC. Neural mobilization and static stretching in experimental sciatica model - an experimental study. Rev Bras Fisioter. 2009;13(6):493-8.

[26] Chan SP, Hong Y, Robinson PD. Flexibility and passive resistance of the hamstrings of young adults using two different static stretching protocols. Scand J Med Sci Sports. 2001 Apr; 11(2):81-6.

[27] H Čolaković, Avdić D. Effects of neural mobilization on pain, straight leg raise test and disability in patients with radicular low back pain. JHS 2013; 3(2):109-112.

[28] Saher M. Efficacy of neural mobilization in treatment of low back pain dysfunction. J Am Sci. 2011:7(4); 566-577

[29] Boland RA, Adams RD. Effects of ankle dorsiflexion on range and reliability of straight leg raising. Aust J Physiother. 2000;46(3):191-200.

[30] Werneke M, Hart DL. Centralization phenomenon as a prognostic factor for chronic low back pain and disability. Spine (Phila Pa 1976). 2001 Apr: 26(7):758-764.

[31] O'Sullivan SB, Schmitz TJ. Physical Rehabilitation: Assessment and Treatment. 5th ed. Philadelphia, PA: F.A. Davis Company; 2006.

[32] Kopec JA, EsdaileJM, Abrahamowicz M, Abenhaim L, Wood-Dauphinee S, Lamping DL et al. The Quebec Back Pain Disability Scale. Measurement properties. Spine (Phila Pa 1976) 1995; 20(3):341-352

[33] George SZ. Characteristics of patients with lower extremity symptoms treated with slump stretching: a case series. J Orthop Sports Phys Ther. 2002 Aug:32(8):391-398.

[34] Cleland JA, Childs JD, Palmer JA, Eberhart S. Slump stretching in the management of non-radicular low back pain: a pilot clinical trial. Man Ther. 2006 Nov $11(4): 279-286$

[35] Silva JT, Santos FM, Giardini AC, Martins DO, Oliveira $\mathrm{ME}$, Ciena AP et al. "In press" Neural mobilization increases nerve regeneration after sciatic nerve injury. J Brachial Plexus and Peripheral Nerve Injury. 2014.

[36] Aina A, May S, Clare H. The centralization phenomenon of spinal symptoms- a systematic review. Man Ther. 2004 Aug;9(3):134-143

[37] Scrimshaw SV, Maher CG. Randomized controlled trial of neural mobilization after spinal surgery. Spine (Phila Pa 1976). 2001 Dec;26(24):2647-2652

[38] Sarkari E, Multani NK. Efficacy of Neural Mobilization in Sciatica. JESP. 2007;3(2):136-141. 